\title{
Efectos psicológicos de los sobre nombres (apodos) en la etapa escolar: Colegio República de Argentina (estudio de caso)
}

Recepción: 25 - 08 - 2015 / Aceptación: 05 - 12 - 2015

Giovanny G Lau.

\section{Resumen}

En la actualidad, atribuir sobre nombres a los escolares es un fenómeno que se está presentando dentro de las escuelas nicaragüenses con la misma frecuencia que el bajo rendimiento académico, el ausentismo, los problemas de relaciones interpersonales entre pares y docentes y la familia. Estas práctica de sobre nombres (o como popularmente se le llama mal apodo) además de ser frecuentes, son una temática sentida por la comunidad. No obstante, existe un vacío bibliográfico, dado que la mayoría de los estudios realizados acerca de los sobre nombres versan sobre aspectos sociolingüísticos y morfosintácticos de las palabras que las personas usan para "sobre nombrar".

En esta investigación se analizaron los efectos psicológicos que tienen los sobre nombres en los estudiantes de educación primaria del Colegio República de Argentina, con el fin de abordar una temática novedosa y pertinente para la población que ha vivido o vive esta situación. Por tal razón, la investigación posee un valor singular al enfocarse, tanto en las vivencias afectivas de los escolares, como en los diferentes efectos que se dan durante el desarrollo de su personalidad por ser sobre nombrados.

Palabras claves: sobrenombres, rendimiento académico, problema social, efectos sicológicos, violencia estudiantil.

\begin{abstract}
Nowadays assigning nicknames to primary students is a situation that is occurring in Nicaraguan's schools with the same frequency as the low academic performance, absenteeism, interpersonal relationships problems among peers and teachers and family. These Nicknames practices besides being frequent, are a subject felt by the community, however there is a literature gap, because most of the studies address sociolinguistic and morph's-syntactical issues

This research analyzes the psychological effects that Nicknames have in school students at Republica de Argentina School, and it aims to address a novel and relevant topic to population. Because of that this research has a unique value when focus both student's emotional experiences and different effects that occur in students personality when they are over named.
\end{abstract}

Keywords: Nicknames, academic performance, social problems, psychological effects, student violence 


\section{El problema de los sobre nombres}

La palabra hablada genera emociones, pensamientos, conductas y tiene repercusiones en el desarrollo de la personalidad, principalmente cuando posee un alto contenido semántico y concierne a la identidad del receptor. Tal es el caso de los sobrenombres, que actualmente son un fenómeno sentido por los docentes y consejeros escolares, pues afirman que son una manifestación de violencia e indisciplina. Lo anterior deja varias dudas; entre ellas ¿por qué tienen tipificados los sobrenombres de esa manera?, ¿cuáles son los criterios para determinar que son una manifestación de violencia y no una manifestación de inclusión social o simplemente algo propio del proceso de socialización de los niños? Para responder estas preguntas, fue necesario conocer qué piensan los involucrados, principalmente los escolares con sobre nombres, pues son ellos quienes pueden decir que tan negativo o positivo es el hecho de ser llamado de una forma diferente a su nombre legal.

El Colegio en estudio, está ubicado en el Distrito VI de la ciudad de Managua. Cuenta con tres turnos: matutino, vespertino y dominical. Tanto en el matutino como en el vespertino se imparten clases en todos los niveles: preescolar, primaria y secundaria. En el dominical, únicamente se imparte clases de secundaria.

El Centro escolar cuenta con una planta docente conformado por 62 maestros distribuido en los tres niveles que cuenta el Colegio; un área administrativa conformada por la directora, subdirectora, personal de apoyo (docentes retirados que ayudan en la secretaría de la dirección), conserje y coordinadoras de turno (dos en la mañana, dos por la tarde y una dominical).

Para el año 2013 el Centro tuvo una matrícula aproximada de 2500 estudiantes. Para el 2014 el centro fue reubicado y dado la situación presentada, la matrícula bajó a 1800 alumnos, de los cuales 142 pertenecen al nivel preescolar, 521 a primaria y los restantes a secundaria matutino, vespertino y dominical.

El propósito de este trabajo consistió en el análisis de los efectos psicológicos de los sobrenombres en escolares del Colegio República de Argentina, Managua, durante el período agosto-diciembre de 2013. Para realizarlo, se hizo una exploración de los conocimientos que los sujetos tienen del estudio acerca de los sobre nombres. De igual manera, la distinción de los tipos de sobre nombres que poseen, la identificación de sus reacciones emocionales, así como sus manifestaciones conductuales al momento de recibir el sobre nombre. Finalmente, se evalúan los efectos del estudiante en esta condición sobre la afectación en la autoestima y en el auto concepto que tienen de ellos mismos.

\section{¿Qué dice la teoría?}

De acuerdo a diversos postulados, tener un sobrenombre en la etapa escolar puede marcar la vida de un individuo de forma única y pudiera ser para toda la vida. Este hecho tiene aspectos positivos y negativos, en dependencia del efecto que provoque, si produce bienestar o contrariamente si degrada la personalidad del sujeto.

Lo anterior, está relacionado a una serie de factores de tipo cultural, el nivel de aceptación, así como por las circunstancias en las que se le asigna. Por ser los sobre nombres la unidad de análisis y dado que aparecen dentro de la dinámica de socialización de los escolares con mucha frecuencia y en formas muy diversas, algunas veces aludiendo a algún defecto, $\mathrm{y}$ en otras ocasiones a cualidades; se han seleccionado algunos conceptos que guían en análisis.

Unas definiciones a las que se han recurrido por el hecho de ser un espacio donde 
confluyen y/o recoge el proceso de evolución de la lengua las cuales están íntimamente relacionadas con la vida cotidiana, es el Diccionario de la Real Academia Española: "Nombre que suele darse a una persona, tomado de sus defectos corporales o de alguna otra circunstancia; chiste o dicho gracioso con que se califica a alguien o algo, sirviéndose ordinariamente de una ingeniosa comparación" (Real Academia Española, 2001).

El sobrenombre o apodo se interpreta también, como un tipo de caricia psicológica que puede tener una forma positiva $o$ negativa en dependencia del tipo emociones que provoque en el receptor. Para efectos de una correcta interpretación al momento de leer este estudio, se utiliza indistintamente la palabra "apodo" como sinónimo de "sobrenombre" de acuerdo a Candia (1997) y al diccionario de la Editorial Océano de 2013.

El concepto de la RAE es claro y bastante sencillo, además muestra una panorámica del uso socio-lingüístico que se le da a los sobrenombres en los diferentes tipos de relaciones interpersonales que pueda haber. El segundo, ha sido construido por mí a partir del postulado teórico del Análisis Transaccional que versa sobre "las caricias".

El análisis transaccional (A.T.) es una teoría de la psicología individual y social, al mismo tiempo que una forma de psicoterapia, creada y desarrollada por Erick Berne. Este autor observó que en cada persona existen tres partes distintas y funcionales, a las que denominó "estados del yo", definidos cada uno como sistemas de emociones y pensamientos acompañados por un conjunto de patrones conductuales. Cada estado del yo tiene una forma distinta de comunicarse, por ello hay diferentes tipos de transacciones y de caricias como se verá a continuación:

\section{Caricias}

De acuerdo con Berne (1965), se denomina "caricia" a todo estímulo dirigido de un ser vivo hacia otro ser vivo, con intencionalidad (destinado a una persona determinada) y posibilidad de respuesta. Comprende todo lo que indique reconocimiento de la otra persona permitiendo la comunicación.

Las caricias de manera general se clasifican en verbales y no verbales. Las primeras están compuestas de material dialéctico, es decir se dirigen mediante el uso de la palabra hablada o escrita y las segundas pueden subdividirse en:

$\checkmark$ Físicas: abrazar, acariciar, golpear.

$\checkmark$ Gestuales: sonreír, guiñar un ojo, hacer una señal con la mano.

Todas las caricias producen sensaciones y emociones, es decir reacciones en las personas que las reciben. Esas sensaciones y emociones pueden ser placenteras o deplorable, razón por la cual las caricias sean verbales o no verbales, desde la perspectiva del receptor, se subdividen en positivas y negativas. La primera genera agrado o placer y la segunda produce molestia, fastidio.

Asimismo, es importante señalar que existen otras sub-categorías de las caricias derivadas de las negativas y positivas. Siendo verbales o no verbales, las caricias también pueden ser:

$\checkmark$ Caricias de lástima: estas fomentan la sensación de desvalimiento, inutilidad o incapacidad.

$\checkmark$ Caricias agresivas: estas fomentan la sensación de sentirse no querido, rechazado.

$\checkmark$ Caricias falsas positivas: son caricias agresivas encubiertas que ocultan la hostilidad y que ponen al receptor en posición de "no estoy bien". 
$\checkmark$ Caricias condicionales e incondicionales: las primeras son los estímulos que se emiten cuando el receptor cumple con alguna cualidad necesaria y las segundas se dan sin condición alguna.

En el caso los sobrenombres al ser palabras, habladas o escritas, se tipifican como caricias verbales, pero su sub-categoría específica dependerá de las emociones que despierten en el sujeto. Así a un niño no vidente al ser apodado como "el cieguito", puede causársele sensación de desvalimiento e inutilidad. Si la sensación del sobrenombre le genera desasosiego, será una "caricia verbal negativa de lástima".

De igual forma el apodo de "chanchoman" otorgado a un niño con problema de sobrepeso (socialmente no aceptado) será una "caricia verbal negativa" pero no de "lástima", sino "agresiva". Esta situación le provoca al niño sentimientos de rechazo y no inutilizado.

Todo tipo de afecto es importante en la vida de los seres humanos, porque existe una necesidad de afecto expresada en caricias $\mathrm{u}$ otras expresiones. No obstante, con el crecimiento y desarrollo físico e intelectual se aprende a recibir diferentes tipos de caricias (verbales y gestuales), influenciado por pautas culturales de nuestra sociedad en la que el contacto físico está permitido solo dentro de ciertos límites y bajo determinadas circunstancias. (Berne, 1966).

Cualquiera que sea la forma de caricias que consiga el niño, se adaptará a ellas porque le aseguran su supervivencia, se acostumbrará y creerá que son las únicas que puede conseguir posteriormente. Fuera de su círculo familiar se relacionará con otras personas que le brinden el mismo tipo de caricias, rechazando o transformando las demás.

\section{Aspectos positivos de los sobrenombres}

Los sobrenombres pueden ser positivos cuando remarcan una habilidad, aptitud o rasgo intelectual, logran reforzar la autoestima y motivar la integración social de los niños. (García citado por Torres, 2011). Siguiendo con Torres, se puede decir que "al destacar las habilidades que poseen los niños para ciertas competencias, concursos, deportes y actividades educativas, refuerzan su seguridad y sentido de pertenencia social.". (Torres, 2011:2).

Además García citado por torres (2011) expresa que en efecto los sobrenombres como "el Lince" son atribuidos a los que destacan por su velocidad en competencias. Otro caso, "la peque" para las niñas menuditas y delgaditas o "Máster" para las habilidosas en determinada área. Ahora bien, el auto concepto puede beneficiar a los niños y niñas al percibirlos (y percibirse asimismo) como una herramienta positiva que los distingue de los demás.

También ciertos sobrenombres como "el oso" lo poseerán aquellos que sean identificados y asociados con la fuerza o corpulencia, o "el 300" por tener un buen físico como los personajes de la película antes mencionada, "el Godzila" por ser grande e impotente; "la enciclopedia" por ser el más estudioso y tener una respuesta para todo. Estos apodos o sobrenombres, en definitiva podrían ayudar a la formación de una autoimagen y un auto concepto óptimo.

Los niños y niñas durante la edad escolar fortalecen su red social, y en ocasiones un sobrenombre es suficiente para ser reconocido por su grupo social. Los tipos de apodos citados con anterioridad, les permiten ser identificados por los demás, incluso por nuevas personas para que sean ubicados fácilmente. 


\section{Aspectos negativos de los sobrenombres}

En lo que se refiere a los aspectos negativos, es importante señalar que los sobrenombres muchas veces remarcan debilidades $y$ defectos. Su uso toma en cuenta la apariencia física, propiedades tales como el color de piel, la estatura, el peso, el tamaño y color de los ojos o el hecho de que se tenga alguna deformidad.

Se dice que los padres de familia que recibieron apodos hirientes cuando eran niños a menudo son más propensos a sentirse temerosos cuando deben elegir el nombre de su bebé, dado que recuerdan el sufrimiento que padecieron. Por ello debe de tenerse algún reparo o análisis, al momento de la elección del nombre a su hijo/hija, de tal manera que no sea blanco de algún apodo que le cause dolor o vergüenza al menor. (Pregnacy-info Net. 2009)

Los sobrenombres hirientes pueden aparecer en las primeras etapas del desarrollo, sobre todo en la escolar y provocan golpes $\mathrm{y}$ traumas. En ocasiones son insultos que destruyen la autoestima, con el paso del tiempo alteran varios componentes de la personalidad, afectan el rendimiento de las habilidades sociales. En la edad adulta lo recuerdan con mucho dolor, a tal punto de llegar a sentir rencores y odios muy arraigados. Toda esta situación puede darse en caso de que el problema no haya sido tratado.

Por otra parte, según Molina (2004) el niño en etapa escolar, posee un pensamiento concreto/operacional que lo caracteriza. Suele creer o tomar todo lo que se le dice como si fuese verdad absoluta, por eso que los sobrenombres ejercen una influencia muy fuerte en la conducta de los niños, pues al ser llamados constantemente con alguna denominación ajena a su nombre real, ellos "asumen " ese apodo como suyo, al aprender que esa es su identidad. La construcción de la identidad individual es aquellos que los vuelven únicos en su forma de pensar, actuar y sentir.

Todos estos procesos están condicionados por las experiencias pasadas en relación con nuestras primeras experiencias de caricias (madre, padre, familia) y nuestras habituales experiencias de caricias (entorno próximo $\mathrm{y}$ entorno cultural). Todo esto repercute en la comunicación de nuestros deseos y preferencias, y con las decisiones personales que tomamos al respecto.

La consecuencia es que todas estas vivencias conforman y estructuran la personalidad tanto interna como externamente. Quedan grabadas junto con los aspectos emocionales y cognitivos que las acompañan, en las distintas estructuras de la personalidad cuando se establecen las relaciones. Tiene un efecto también en la socialización de los individuos y su dirección (positiva o negativa) dependerá --como se ha dicho anteriormente-- de los tipos de caricias que se reciban a lo largo de las primeras etapas y al ser los sobrenombres una de ellas, también tendrán una fuerte influencia en la vida de las personas.

\section{Metodología aplicada}

Ante los contrastes teóricos, donde se pueden observar planteamientos positivos y negativos de los sobrenombres, se decidió emplear un enfoque cualitativo y fenomenológico que estudia el fenómeno tal y como se vive en la cotidianidad. De corte transversal, se utilizó la observación directa no participante y la entrevista en profundidad, aplicada tanto a la población en estudio, como a las maestras informantes clave y expertos en el tema.

Para el estudio se utilizó un muestreo no probabilístico de tipo intencional (discrecional), seleccionado casos 
representativos del grupo focal. Se eligieron seis escolares del turno matutino, quienes tenían mayor riqueza de información para dar respuesta a los objetivos del estudio.

Asegurando el cumplimiento de las leyes y normativa de protección de la niñez y la adolescencia, se realizó una visita al centro educativo para realizar una reunión de padres de familia para obtener la autorización a fin de que los niños y niñas participaran en la investigación..

Posteriormente se realizó una entrevista a profundidad, para conocer aspectos personales, sociales y académicos generados a partir del hecho de poseer un sobrenombre. Cabe señalar que las entrevistas a profundidad fueron realizadas al aire libre en el patio del centro y en los pasillos del centro escolar.

Adicionalmente, se realizó entrevista a especialistas: una psicóloga educativa, pedagoga en educación primaria y a una psicóloga que es consejera escolar del Ministerio de Educación.

Para tener conocimientos sobre los aspectos psicológicos y socioculturales del fenómeno de estudio, se entrevistó informantes claves, como la coordinadora y una de las profesoras de primaria del turno matutino del Colegio República de Argentina,

A partir de la lectura de los datos, se procedió a elaborar las categorías de análisis, entre ellas sobrenombres, tipos de sobrenombres, surgimiento de los sobrenombres, reacciones afectivas antes los sobrenombres, manifestaciones conductuales de los sobrenombres, efectos psicológicos de los sobrenombres.

De acuerdo a los datos obtenidos se procedió a triangular la información del grupo focal, de las entrevistas en profundidad a los sujetos de la muestra, informantes claves y expertas, lo que permitió describir los efectos psicológicos que tienen los escolares con relación al fenómeno de los sobrenombres. De todo este trabajo, a continuación se da a conocer un compendio de los resultados.

\section{Resultados del estudio}

Después de un exhaustivo análisis de los resultados, se pudo evidenciar que:

$\checkmark$ Los escolares del grupo focal y los informantes claves de este estudio tienen poco conocimientos acerca los sobrenombres.

$\checkmark \quad$ Los escolares de la muestra y las expertas coinciden en que los apodos suelen darse en el colegio, la comunidad y en la familia, ya sean estos con buena o mala intención.

$\checkmark$ Para la mayoría de los sujetos del estudio los sobrenombres que ellos tienen son negativos porque aluden sus características físicas en forma despectiva y esto les hace sentir mal.

$\checkmark$ Las reacciones emocionales que experimentan los escolares de la muestra, al ser sobre nombrados, es de desagrado de fastidio. Las principales registradas fueron: enojo, la tristeza, vergüenza y deseos de venganza.

$\checkmark$ Las emociones desagradables que viven los escolares están íntimamente asociadas al tipo de sobrenombre que poseen.

$\checkmark$ Las manifestaciones conductuales más frecuentes de los escolares al ser llamados por sus sobrenombres, son el llanto, los golpes, el uso de un lenguaje inapropiado y las quejas o denuncias. 
Según los escolares de la muestra, informantes claves y expertas, existe afectación en la autoestima y auto concepto.

$\checkmark$ El rendimiento académico en los escolares se ve afectado, ya que se les dificulta concentrarse en clase, sienten apatía por llegar al Colegio lo que los lleva a la desmotivación escolar (absentismo), y tener un comportamiento inapropiado, baja en las calificaciones.

$\checkmark$ La socialización para los sujetos en estudio se ve afectada, adoptan una actitud agresiva y violenta con el resto de sus compañeros de clase, vecinos y amigos, hasta el punto de aislarse.

\section{Recomendaciones}

De acuerdo a los resultados de esta investigación, se llegaron a las siguientes recomendaciones:

A los escolares que han sido víctimas de sobre nombres:

$\checkmark$ Romper el silencio. Es preciso que los escolares dialoguen con sus tutores legales y expresen por qué consideran importante que intervengan.

$\checkmark$ Agotar siempre las instancias institucionales interponiendo la correspondiente denuncia en las instancias apropiadas, incluso en caso de no ser escuchada en las instancias intermedias, llegar hasta las oficinas del Ministerio de Educación.

$\checkmark$ Para el control de sus emociones negativas producto de la condición en que viven, llevar un cuaderno-diario donde describan la situación acerca de cómo ocurrió todo, cómo se sintieron al respecto y cómo querían responder.

A las autoridades del centro de estudio motivo de esta investigación:

$\checkmark \quad$ Implementar políticas que apunten a la eliminación del uso de sobrenombres en toda la comunidad educativa.

$\checkmark$ Brindar capacitaciones a los docentes en el manejo de las quejas y el abordaje de los estudiantes que sufren por un sobrenombre.

$\checkmark \quad$ Identificar a los escolares que posean un sobrenombre, para llevar un seguimiento de su comportamiento, y luego brindarles el abordaje adecuado.

Brindar charlas a los escolares con sobrenombres sobre las habilidades sociales con énfasis en la asertividad.

$\checkmark$ Identificar a aquellos escolares que hacen uso de los sobre nombres para llamar a sus compañeros (as).

$\checkmark \quad$ Brindar charlas acerca de la empatía y el interés social a los escolares que recurran a los sobre nombres para llamar a otros.

$\checkmark$ Abrir espacios de diálogo donde los escolares con sobre nombres puedan expresar de manera libre su estado anímico ante la situación que están viviendo.

$\checkmark \quad$ Implementar un programa de mediación en el que los escolares con sobre nombres y escolares que sobre nombran puedan resolver sus diferencias por la vía pacífica de la asertividad.

$\checkmark$ Promover el uso del lenguaje respetuoso, 
no descalificativo ni discriminatorio entre las y los niños; así como del profesor hacia el alumno (a).

\section{Conclusiones}

Con este estudio se logró ampliar el campo de aplicación de la Teoría del Análisis Transaccional. La aplicación de esta teoría demuestra la importancia e incidencia que tiene la ciencia de la psicología en la explicación de fenómenos sociales, en este caso, delimitado al área educativa y de los apodos como una forma de acoso.

Se pudo evidenciar el poder que tiene la palabra hablada como estímulo verbal (material dialéctico) y no verbal (tono de voz) de un ser humano a otro generando emociones, pensamientos y conductas diversas. De igual manera, provocando un impacto directo sobre la psiquis trastocando el desarrollo de la personalidad y la socialización, en edades tempranas como es la etapa escolar.

Por esta razón, la selección de palabras para nombrar a otros no es un asunto que deba tomarse a la ligera. Todas las personas tienen la responsabilidad de cuidar y hacer un buen uso del poder que se tiene sabiendo que todo ello afecta la psiquis de los demás.

\section{Referencias bibliográficas}

\section{Literatura Impresa.}

Cloninger C. Susan (2003) Teorías de la Personalidad, tercera edición, México. Pearson Educación.

Craig Grace (2001) Desarrollo Psicológico, octava edición, México. Pearson educación.

Farré Josep (2003) Enciclopedia de la Psicología, primera edición, España. Oceano.

Feldman, S. Robert (2008) Desarrollo en la Infancia, cuarta edición, México. Pearson educación.

Harre, R. (1980) Que es un sobrenombre, psichology today. pp.78-84.

Hernández Sampieri Roberto et al. (2006) Metodología de la Investigación, quinta edición. Impreso en Perú, editorial empresa editora el comercio S.A.

Prada Rafael (1986) Sea Usted Terapeuta, escuelaspsicológicas ysicoterapéuticas, segunda edición, Bogotá - Colombia, Ediciones paulinas.

Woolfolk Anita (1998) Psicología Educativa, séptima edición, México. Pearson educación.

Web-grafía.

Cuadra Jesús (2005) "Caricias y Estructuras de la Personalidad", consultado el 03 de octubre del 2013 desde: www.bernecomunicacion.net/pdf/ berne106.pdf

Candia P. (1977 "el apodo en Bolivia. La paz", ediciones Isla, consultado el 14 de octubre 2013 desde: : http:// wWw.monografias.com/trabajos93/ semiotica-apodos-un-estudioidentidad-sociedad-boliviana/ semiotica-apodos-un-estudioidentidad-sociedad-boliviana. shtml\#ixzz2vxwMCV61

Durán Wilson David (2010) “Hacia El Análisis Sociolingüístico Del Apodo En El Habla Juvenil De Diversas Capas Sociales En La Ciudad De PEREIRA: Un Estudio De Caso", consultado el 15 de octubre desde: recursosbiblioteca.utp.edu.co/ tesisdigitales/texto/3022242D948.pdf

Espinoza Ricardo (2009) "los catrachos son de honduras y ¿los chapines". El sol de México, consultado el 28 de diciembre del 2013 desde: http://www.oem. com.mx/oem/notas/n1151930.htm

Gades "yo Autoestima, Autoconcepto", plan de acción tutorial. Consultado 24 de noviembre del 2013: http:// www.juntadeandalucia.es/ 
averroes/html/portal/com/bin/ contenidos/B/ProfesoradoEnRed/ OrientacionEducativa/ Seccion/Programas/ programas/1203419586393 wysiwyg_1161788185681_gades.pdf

Mayán María (2001) “Una Introducción a los Métodos Cualitativos". Consultado el 20 de septiembre de 2013 desde: http://cisolog.com/sociologia/ una-introduccion-a-los-metodoscualitativos/

Molina Cristián et al. (2004) Imagen corporal y desarrollo del sí mismo. Observaciones clínicas en estudiantes secundarios. Universidad católica de chile Sta. Magdalena. Consultado el jueves 09 de diciembre del 2012 desde:http:// www.psicologiadelaemergencia.cl/ imgcorp.htm

Pregnacy-info. Net. (2009) "Apodos hirientes", consultado el 23 de octubre del 2012 desde:http://espanol. pregnancy-info.net/apodos_hirientes. html

Real Academia Española (2001) Apodo,
Diccionario de la lengua española (DRAE), consultado en agosto del 2013 desde: http://lema.rae.es/ drae/?val=apodo

Real Academia Española (2001) Sobrenombre, Diccionario de la lengua española (DRAE), consultado en agosto del 2013 desde: http://lema.rae.es/ drae/?val=sobrenombre

Suría Raquel (2010-2011) Socialización y Desarrollo Social. psicología social (sociología). Curso, consultado el 28 de octubre del 2013 desde: rua.ua.es/.../TEMA \% 202\% 20 SOCIALIZACIÓN \% 20 Y \% 20 DESARROLL...

Torres María Fernanda (2011)"Los apodos, ¿Los apodos tienen algo bueno?", consultado en diciembre del 2012 desde: http://conairefederal.blogspot. com/2011/01/los-apodos.html 